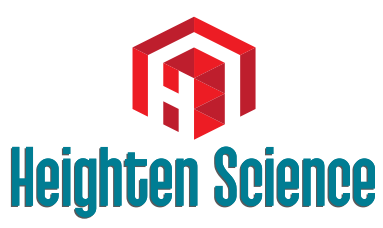

P U B L I C A T I O N S Corporation
*Address for Correspondence: Awad Magbri, Dialysis Access Center of Pittsburgh, PA, USA Email: elmagbri@hotmail.com

Submitted: 16 November 2017

Approved: 15 December 2017

Published: 18 December2017

Copyright: @ 2017 Magbri A, et al. This is an open access article distributed under the Creative Commons Attribution License, which permits unrestricted use, distribution, and reproduction in any medium, provided the original work is properly cited

Keywords: Hepato-pulmonary syndrome; Porto-pulmonary hypertension; Hypoxemia; Cirrhosis; End-stage renal disease; Contrast echocardiography; Pulmonary arterial pressure; Left ventricular end-diastolic volume; Pulmonary hypertension

Check for updates
Case Report

\section{Hepato-Pulmonary syndrome and Porto-Pulmonary Hypertension: Rare combination cause of Hypoxemia in patient with end-stage renal failure on Hemodialysis and hepatitis C Induced Decompensated Cirrhosis}

\author{
Awad Magbri*, Mariam El-Magbri and Eussera El-Magbri \\ Dialysis Access Center of Pittsburgh, PA, USA
}

\section{Case Report}

The case is that of 83 year-old African American man with hypertension, hepatitis $\mathrm{C}$ induced decompensated cirrhosis with ascites, end-stage renal disease (ESRD) on hemodialysis, fluid overload with peripheral edema and chronic hypotension. The patient was referred to the dialysis access center of Pittsburgh, PA for evaluation of his prolonged bleeding from the left upper arm brachial-basilic arterial-venous fistula (BBAVF).

On examination, he was found to be severely hypoxic with oxygen saturation of 80-92 mm Hg. Chest was clear on auscultation. Abdominal examination showed hepatosplenomegaly with ascites. Extremities showed 3+ peripheral edema bilaterally. His chest x-ray showed cardiomegaly with clear lung fields. His laboratory workup showed, WBC of 3.4, RBC 3.69, MCH 31.2, MCHC 32, and platelets $104 \mathrm{~K} / \mathrm{L}$. Chemistry showed Na 134, Cl 99, CO2 24, Total protein 7.2 with albumin of 2.9. SGOT was high at 44, vitamin D 42. Laboratory data were also indicative of chronic liver disease with bilirubin of 2.8, INR of 1.2, and albumin of 2.9, and platelet count of 104. Immunology for Hepatitis B Ag was negative, Hepatitis B Ab was $22 \mathrm{H}$, Hepatitis C Ab was positive. Arterial blood gas analysis showed $\mathrm{PaO} 2$ of $54 \mathrm{mmHg}$ while breathing room air.

Abdominal ultra-sound revealed features suggestive of portal hypertension (hepatosplenomegaly with ascites). Transthoracic echocardiogram showed elevated right ventricular systolic pressure of $52 \mathrm{mmHg}$ with mild-moderate dilatation of the right atrium and right ventricle with normal left ventricular function. A contrast echocardiogram was suggestive of hepatopulmonary syndrome (appearance of the bubbles in the left ventricle after 5 beats of their appearance in the right ventricle). Right heart catheterization was not done but his angiogram revealed reflux of dye into the right innominate vein up to the subclavian vein and right IJ. Other causes of pulmonary hypertension were excluded on history and clinical examination.

\section{Discussion}

Hepatic diseases are associated with 3 main pulmonary syndromes associated with portal hypertension:

1. Porto-pulmonary hypertension (POPH), pulmonary arterial hypertension in the absence of other causes. 
2. Hepatopulmonary syndrome (HPS), pulmonary arterial vascular dilatation with a defect in arterial oxygenation.

\section{Hepatic hydrothorax.}

The incidence of POPH and HPS in patients with liver disease are (0-7\%), and (429\%) respectively [1]. However, the co-existence of POPH and HPS is rare but has been previously reported in 2 case reports [1,2]. Many theories have been put forward to explain POPH and HPS related to pulmonary hemodynamic alteration in patients with liver diseases. One of these theory is up-regulation of inflammatory response in patients with portal hypertension which leads to increased endothelin receptors and vasoconstriction without hypoxemia [1]. On the other hand, HPS is associated with vasodilation causing intra-pulmonary shunts of blood leading to hypoxemia [2,3]. It is ironic that both POPH and HPS can co-exist in the same patient as the underlying mechanisms are antagonistic. The explanation that have been circulating is that there is up-regulation of type B-endothelin receptors in HPS with increased nitric oxide and dilation of the pulmonary vessels with shunting and hypoxemia [2,3]. HPS is associated with hypoxemia in the up-right position and platypnea (dyspnea induced by up-right position and relived by recumbency). Measurement of $\mathrm{SaO} 2$ with portable pulse oximeter at ambient 02 partial pressure in supine position compared with upright position after 10 minutes can help in screening patients who might have HPS. The criteria for further additional tests rest on the followings [4];

- $\mathrm{SaO} 2 \leq 92 \%$ in supine position

- A decrease in $\mathrm{SaO} 2$ of $\geq 4 \%$ after change from supine to the upright position $(\triangle \mathrm{Sa} 02)$ If these criteria are met then patients undergo the following;

- Chest x-ray

- Pulmonary function test

- Trans-thoracic contrast enhanced echocardiography (CEE)

- Perfusion lung scan

In $\mathrm{POPH}$, on the other hand there is up-regulation of A-type endothelin receptors leading to pulmonary arterial vasoconstriction causing vascular remodeling and development of pulmonary hypertension [1,3]. Dyspnea on exertion and increased pulmonary arterial pressure (PAP) in patients with portal hypertension are characteristics of POPH [3]. Diagnosis is confirmed by right heart catheterization which showed;

1 Mean PAP $>25 \mathrm{mmHg}$ at rest, or $>30 \mathrm{mmHg}$ on exertion.

2 Increased pulmonary vascular resistance $>250$ dyne $/ \mathrm{CM}^{2}$.

3 Trans-pulmonary gradient, the difference between mean PAP and pulmonary capillary wedge pressure (PCWP) $>12 \mathrm{mmHg}$.

4 Left ventricular end diastolic pressure of $<15 \mathrm{mmHg}$ in the absence of other causes of PAH [3].

Pulmonary hypertension $(\mathrm{PH})$ is common in patients chronic kidney disease (CKD) stage-5 (9-39\%) and end-stage renal disease on hemodialysis (18.8-68.8\%), and (0$42 \%$ ) in peritoneal dialysis [5-15]. Pulmonary hypertension in CKD-5 or ESRD on HD may be induced or aggravated by left ventricular dysfunction, volume overload [16-18], an arterial-venous fistula [7,11,19-23], sleep disorders [24-30], exposure to dialysis membranes [31], endothelial dysfunction [32], vascular calcification and stiffness, and severe anemia. Controlling volume overload and left ventricular disorders are important for relieving PH. Preventing PH in these patients are important because kidney transplant may not reverse the high mortality associated with established PH. 
Diagnosis of HPS in patient with portal hypertension and hypoxemia is supported by the following;

1. $\mathrm{PaO}_{2}<80 \mathrm{mmHg}$

2. Alveolar-arterial gradient $>15 \mathrm{mmHg}$ on room air adjusted for age [33].

3. Contrast echocardiography evidence of pulmonary shunting (appearance of agitated saline in the left atrium after 3 cardiac cycles), [33,34].

Treatment of POPH and HPS are different;

The mainstay of treatment of POPH is pulmonary vasodilation;

1. Intra-venous epoprostenol which causes improvement in hemodynamics and symptoms in POPH but needs constant intra-venous access for drug infusion and highly compliant patient [35].

2. Oral or nebulized prostacyclin [36].

3. Oral dual endothelin receptor antagonist (bosentan), which has beneficial effect on exercise capacity and hemodynamics in POPH [35].

Pulmonary hypertension in cirrhotic patients with portal hypertension carries a poor prognosis and high mortality after liver transplantation [3]. A mean PAP of $50 \mathrm{mmHg}$ is contraindication to liver transplantation [3]. An aim of PAP of $<35 \mathrm{mmHg}$ is necessary if liver transplant is contemplated in cirrhotic patients. The 5-year survival of POPH is $14-45 \%$ of those receiving medical treatment. PH in ESRD patients is usually of the WHO class-II (PH secondary to left ventricular dysfunction). Vasodilator therapy which is currently is recommended for WHO class-I patients is contra-indicated in CKD-5 and ESRD because of increased mortality. PH due to left ventricular dysfunction has been ruled out in our patients because of low left ventricular end diastolic pressure however, the accuracy of echocardiography diagnosis in these cases is debatable.

Treatment of HPS is based on correction of hypoxemia with oxygen and liver transplantation which is the only measure to alter the natural course of the disease and improve the hypoxemia [33]. However, persistent hypoxemia in patients with HPS carry a high morbidity and mortality in cirrhotic patients who contemplating liver transplantation [33]. The 5-year survival of HPS without liver transplant is 23\% [33].

The treatment of both POPH and HPS when co-exist in the same patient is challenging. These patients usually, have multiple co-morbidities and are not candidates for liver transplantation. Even though, liver transplantation can cure both syndromes but is contra-indicated in patients with high POPH. Whether combined lung and liver transplantation can be used in patients with high POPH is a matter for discussion. More studies are needed to tackle the co-existence of both syndromes in patients with portal hypertension (Figures 1,2).

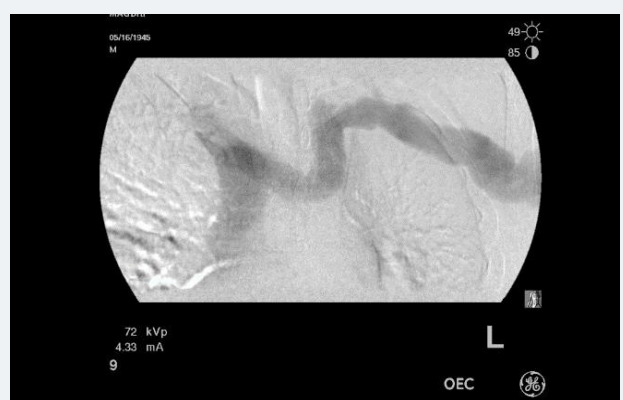

Figure 1: 


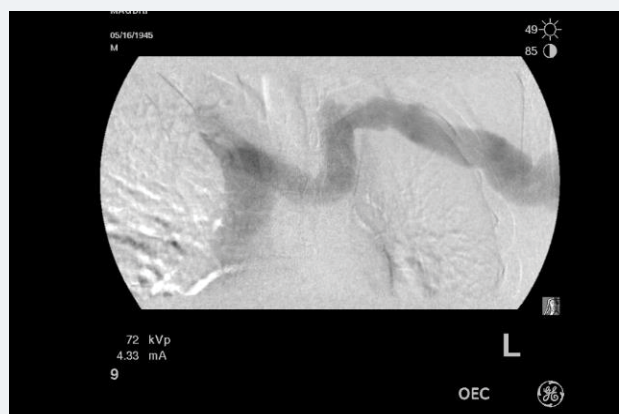

Figure 2:

\section{References}

1. Pham DM, Subramanian R, Parekh S. Coexisting hepatopulmonary syndrome and portopulmonary hypertension. J Clin Gastroenterol. 2010; 44: 135-140. Ref.: https://goo.gl/QegECL

2. Toya S, Schraufnagel DE. Hepatopulomonary syndrome and pulmonary hypertension in the same patient: a pathophysiological paradox and therapeutic dilemma. Respiratory Medicine Extra. 2006; 2: 23-26. Ref.: https://goo.gl/JGQLKr

3. Feltracco P, Serra E, Brezzi M, Milevoj M, Rizzi S, et al. Hemodynamic profile of portopulmonary hypertension. Transplant Proceedings. 2009; 41: 1235-1239. Ref.: https://goo.gl/yexq9K

4. Whyre MK, Hughes JM, Peters AM, Ussov W, ShetalPatel, et al. Analysis of intrapulmonary right to left shunt in the hepatopulmonary syndrome. J Hepatol. 1998; 29: 85-93. Ref.: https://goo.gl/8tYDB5

5. Badesch DB, Champion HC, Sanchez MA, Hoeperet MM, Loyd JE, et al. Dignosis and assessment of pulmonary arterial hypertension. J AM Coll Cardiol. 2009; 54: S55-S66. Ref.: https://goo.gl/j9YLGx

6. Pabst S, Hammerstringl C, Hundt F, Gerhardt T, Grohé C, et al. Pulmonary hypertension in patients with chronic kidney disease on dialysis and without dialysis: results of the PEPPER-study. PLoS One. 2012; 7: 35310. Ref.: https://goo.gl/bjjjhG

7. Yigla $M$, Fruchter $\mathrm{O}$, Aharonson D, Noa $\mathrm{Y}$, Shimon A.Reisner, et al. Pulmonary hypertension is an independent predictor of mortality in hemodialysis patients. Kidney Int. 2009; 75: 969-975. Ref.: https://goo.gl/YEmGP8

8. Ramasubbu K, Deswal A, Herejurgen C, Aguilar D, Frost AE. A prospective echocardiographic evaluation of pulmonary hypertension in chronic hemodialysis patients in the United States: prevalence and clinical significance. Int J Gen Med. 2010; 3: 279-286. Ref.: https://goo.gl/885Eag

9. Bozbas SS, Akcay S, Altin C, Bozbas H, Karacaglar E, et al. Pulmonary hypertension in patients with end-stage renal disease undergoing renal transplantation. Transplant proc. 2009; 41: 2753-2756. Ref.: https://goo.gl/YG15U1

10. Etemadi J, Zolfaghari $H$, Firoozi $R$, Ardalan MR, Toufan $M$, et al. Unexplained pulmonary hypertension in peritoneal dialysis and hemodialysis patients. Rev Rort Pneumol. 2012; 18: 10-14. Ref.: https://goo.gl/dSfm9A

11. Fabbian F, Cantelli S, Molino C, Pala M, Longhini C, et al. Pulmonary hypertension in dialysis patients: a crosssectional Italian study. Int J Nephrol. 2010; 11: 463-475. Ref.: https://goo.gl/AqcsAu

12. Zlotnick DM, Axelrod DA, Chobanian MC, Scott Friedman, Brown J, et al. Noninvasive detection of pulmonary hypertension prior to renal transplantation is a predictor of increased risk for early graft dysfunction. Nephrol Dial Transplant. 2010; 25: 3090-3096. Ref.: https://goo.gl/PXpv5p

13. Kumbar L, Fein PA, Rafiq MA, Borawski C, Chattopadhyay J, et al. Pulmonary hypertension in peritoneal dialysis patients. Adv Perit Dial. 2007; 23: 127-131. Ref.: https://goo.gl/rgLpN3

14. Agarwal R. Prevalence, determinants and prognosis of pulmonary hypertension among hemodialysis patients. Nephrol Dial transplant. 2012; 27: 3908-3914. Ref.: https://goo.gl/6XNkoT

15. Kiykim AA, Horoz M, Ozcan T, Yildiz I, sari S, et al. Pulmonar hypertension in hemodialysis patients without arteriovenouws fistula: the effect of dialyzer composition. Ren Fail. 2010; 32: 1148-1152. Ref.: https://goo.gl/LBh6sy

16. Evans AM, Hardie DG, Peers C, Mahmoud A. Hypoxic pulmonary vasoconstriction: mechanism of oxygen-sensing. Curr Opin Anaesthesiol. 2011; 24: 13-20. Ref.: https://goo.gl/jiHBPQ

17. Sakao S, Tatsumi K, Voelkel NF. Reversible of irreversible remodeling in pulmonary arterial hypertension. Am J Respir Cell Mol Biol. 2010; 43: 629-634. Ref.: https://goo.gl/5e121z 
18. Halpern SC, Taichman DB. Misclassification of pulmonary hypertension due to reliance on pulmonary capillary wedge pressure rather than left ventricular end-diastolic pressure. Chest. 2009; 136: 37-43. Ref.: https://goo.gl/KTDtnJ

19. Issa N, Krowka MJ, Griffin MD, Hickson LJ, Stegall MD, et al. Pulmonary hypertension is associated with reduced patient survival after kidney transplantation. Transplantation. 2008; 86: 1384-1388. Ref.: https://goo.gl/vdXAyz

20. Abdelwhab S, Elshinnawy S. Pulmonary hypertension in chronic renal failure patients. Am J Nephrol. 2008; 28: 990-997. Ref.: https://goo.gl/1DC8HT

21. Yigla M, Nakhoul F, Sabag A, Tov N, Gorevich B, et al. Pulmonary hypertension in patients with endstage renal disease. Chest. 2003; 123: 1577-1582. Ref.: https://goo.gl/9dzV6a

22. Havlucu Y, Kursat S, Ekmekci C, Celik P, Serter S, et al. Pulmonary hypertension in patients with chronic renal failure. Respiration. 2007; 74: 503-510. Ref.: https://goo.gl/k27LBh

23. Abassi Z, Nakhoul F, Khankin E, Reisner SA, Yigla M. Pulmonary hypertension in chronic dialysis patients with arteriovenous fistula : pathogenesis and therapeutic prospective. Curr Opin Nephrol Hypertens. 2006; 15: 353-360. Ref.: https://goo.gl/ygMuL7

24. Sakaguchi $Y$, Shoji $T$, Kawabata $H$, Niihata K, Suzuki A, et al. High prevalence of obstructive sleep apnea and its association with renal function among nondialysis chronic kidney disease patients in Japan: a cross-sectional study. Clin J Am Soc Nephrol. 2011; 6: 995-1000. Ref.: https://goo.gl/p5i3Nb

25. Zoccali C, Mallamaci F, Tripepi G. Nocturnal hypoxemia predicts incident cardiovascular complications in dialysis patients. J AM Soc Nephrol. 2002; 3: 729-733. Ref.: https://goo.gl/3VLjqU

26. Sica AL, Greenberg HE, Ruggiero DA, Scharf SM. Chronic intermittent hypoxia: a model of sympathetic activation in the rat. Respir Physiol. 2000; 121: 173-184. Ref.: https://goo.gl/YLvv1q

27. Barcelo A, de la Pena M, Ayllon O, Vega-Agapito MV, Piérola J, et al. Increased plasma levels of asymmetric dimethylarginine and soluble CD40 ligand in patients with sleep apnea. Respiration. 2009; 77: 85-90. Ref.: https://goo.gl/2ZrwkF

28. Grassi G, Seravalle G, Ghiadoni L, Giovanni T, Rosa MB, et al. Sympathetic nerve traffic and asymmetric dimethylarginine in chronic kidney disease. Clin J Am Soc Nephrol. 2011; 6: 2620-2627. Ref.: https://goo.gl/BjivP5

29. Mallamaci F, Tripepi G, Maas R, Malatino L, Boger R, et al. Analysis of the relationship between norepinephrine and asymmetric dimethylarginine levels among patients with end-stage renal disease. J Am Soc Nephrol. 2004; 15: 435-441. Ref.: https://goo.gl/9PpjHh

30. Tripepi G, Mattace Raso F, Sijbrands E, Mohamed SS, Renke Maas, et al. Inflammation and asymmetric dimethyl arginine for predicting death and cardiovascular events in ESRD patients. Clin J Am Soc Nephrol. 2011; 6: 1714-1721. Ref.: https://goo.gl/UvfN7M

31. Yigla M, Abassi Z, Reisner SA, Nakhoul F. Pulmonary hypertension in hemodialysis patients: an unrecognized threat. Semin Dial. 2006; 19: 353-357. Ref.: https://goo.gl/DNKpHs

32. Giaid A. Nitric oxide and endothelin-1 in pulmonary hypertension. Chest. 1998; 114: 208-212. Ref.: https://goo.gl/8XaUqn

33. Macedo IG, Lopes EP. Hepatopulmonary syndrome. San Paulo Medical Journal. 2009; 127: 223-230. Ref.: https://goo.gl/15gzrL

34. Hopkins WE, Waggoner AD, Barzilai B. Frequency and significance of intrapulmonary right to left shunting in end stage liver disease. Am J Cardiol. 1992; 70: 516-519. Ref.: https://goo.gl/vybP1A

35. Hoeper MM, Krowka MJ, Strassburg CP. Portopulmonary hypertension and hepatopulmonary syndrome. Lancet. 2004; 363: 1461-1468. Ref.: https://goo.gl/uqiZAK

36. Austin MJ, Mcougall NI, Wendon J, Elizabeth S, Knisely AS, et al. Safety and efficacy of combined use of sildenafil, bosentan and lloprost before and after liver transplantation in severe portopulmonary hypertension. 2008; 14: 287-291. Ref.: https://goo.gl/ogoZkJ 